\title{
The Relationship among Parenting Styles, Academic Self-concept, Academic Motivation and Students' Academic Achievement in Fasilo Secondary School: Bahir Dar, Ethiopia
}

\author{
Asrat Dagnew*
}

Faculty of Education and Behavioral Science, Bahir dar University, P.O. Box: 79, Bahir Dar, Ethiopia

\begin{abstract}
The main purpose of this research was to examine the relationship among the parenting styles, academic self concept, academic motivation and students' academic achievement. The sample for this research consisted of 136 from Fasilo secondary school students using stratified random sampling of which 82 males and 54 females from a population of 970 students consisting grade $9^{\text {th }}$ and $10^{\text {th }}$. Data analysis was done descriptively by using the means and standard deviations. Besides that, inferential statistical methods such as the Pearson-r, Multiple Regression and independent t-test techniques were also used to determine the relationship between the factors analyzed. Research results revealed that out of the four specific parenting styles, the authoritative style has the medium correlation ' $r$ ' value that is 0.327 at the significance level of 0.05 with academic achievement. The authoritarian style also has negative significant relationship with achievement, with ' $r$ ' value of -0.225 at the significance level of 0.05 with academic achievement. Besides that, the permissive parenting style has negative significant relationship with achievement, with its ' $r$ ' value of -0.366 at the significance level of 0.05 with academic achievement. However, there is no significant relationship between the neglectful parenting styles with achievement. Results also show that there is a significant relationship among the academic self concept $(r=0.209)$, intrinsic motivation $(r=0.248)$, extrinsic motivation $(r=0.222)$ with academic achievement at the significance level of 0.05 . The multi-regression analysis indicated that authoritative, Authoritarian, permissive, neglected, self-concept, intrinsic motivation and extract motivation were affected by $47.6 \%$ of the variable in the academic achievement, so that great attention was given for the contribution of parenting styles, self-concept and academic motivation for academic achievement. The two-sample t-test indicated that as group males scored significantly higher academic achievement than females in all predictor variables. However, Female students scored high mean score than male counterparts in Authoritative, Authoritarian, Permissive, Self-concept, Intrinsic motivation and extrinsic motivation. On the other, there was no difference mean between males and females with respect to neglectful parenting style and academic achievement was found to be statistically not significant. Based on the findings of the study, it is recommended that, at the school level parent education programs should be incorporated and parents and teachers should come together as collaborators in enhancing the academic achievement of students.
\end{abstract}

Article Information

Article History:

Received : 15-07-2015

Revised : 18-09-2015

Accepted : 25-09-2015

Keywords:

Academic Achievement

Academic self-content

Parenting style

Intrinsic Motivation

Extrinsic Motivation

${ }^{*}$ Corresponding Author:

Asrat Dagnew

E-mail:

asratboza@yahoo.com

Copyright@2015 STAR Journal, Wollega University. All Rights Reserved.

\section{INTRODUCTION}

Education is the process of instruction aimed at the development of the individual, facilitating realization of self-potential and hidden talents of an individual. Education makes a man a right thinker and a correct decision-maker. It is through education that knowledge and information is received and spread throughout the world. In other words, Khan (2003) cited in Kamble (2009) suggested that "without education, man is as though in a closed room and with the education he finds himself in a room with all its windows open towards outside world".

In the current situation, education has a pivotal role to play in the economic and social development of any nation. Bearing in mind the importance of education it is the need of the hour to promote the academic achievement of students, who form the concrete foundation for the country's progress.

Academic achievement is defined as the performance of the students in the subject they study in the school that means academic achievement determines the student's status in the class. It gives children an opportunity to develop their talents, improve their grades and prepare for the future academic challenges. It is common practice to promote students from one class to another on the basis of academic achievement. Academic achievement helps in declaring students successful or unsuccessful, choosing students for various courses and selecting 


\section{Asrat Dagnew}

students for different jobs. It is the level of learning in a particular area of the subject in terms of knowledge, understanding, skill and application usually evaluated by teachers in the form of test scores in their annual examination.

According to Bandura (1997), academic achievement consistently relates to positive identity structures. Academic achievement encompasses self-esteem, selfefficacy, and motivation. On the same source, Zimmerman (2002) revealed that academic achievement can be defined as self-regulated learning, including excellence in sports, arts, culture, behaviour, confidence, and communication skills, and it shows how learners control their emotion, feelings, and actions in order to academically achieve better. Also, Dweck and Elliott (1983) cited in Watabe $(2011$,$) proposed that$ "achievement" is conceptualized in terms of "competence." In an educational setting, success is measured by academic achievement, or how well a student meets standards set out by local government or the institution itself. In primary and secondary schools of Ethiopia, academic achievement always measured by students' examination result, it is not only the examination held by local government such as regional exams and Ethiopian General Secondary Examination Certificate, But also the monthly test, midterm test or standardized test which conducted by the school or district.

The findings of different research studies focused that student performance is affected by different factors such as students' academic self concept, academic motivation and parenting style because the new paradigm about learning assumes that all students can and should learn at higher levels, but it should not be considered as a constraint because there are other factors like race, parents' socioeconomic status, teachers' expectancies, gender, learning abilities, effects of peer relationships etc. that can affect students' performance.

Although there are many types of variables that could affect academic achievement at different levels of schooling, this study has considered the effect of parenting styles, academic self concept and academic motivation on students' academic achievement in Bahir Dar woreda at Fasilo secondary school.

An academic self concept is defined as how a person feels about himself or herself within a school or academic setting, or in relation to a students' academic progress. The academic self concept is the whole assumption of someone on himself. This concept is built since little and from time to time it develops through the self judging process. Therefore, how parents interact, judging and appreciate their children will have a big impact on the building of their children's self concept (Woolfolk, 1995).

Achievement and positive change in the learners' academic achievement is possible only when the learner is motivated. Regarding this as cited in Amare (2001) Cole and Chan (1994) explained that motivation is concerned with personal energy directed towards the achievement of particular goals. According to them, it is a key element of education and plays a critical role in the success for individual students.

In fact, several studies conducted by Tella (2007) and Broussard (2002) indicated that motivation has different
Sci. Technol. Arts Res. J., July-Sep 2015, 4(3): 215-221

effects on students' academic achievement. These researchers have suggested that the only motivation directly affects academic achievement and all other factors affect achievement only through their effect on motivation and the idea common to them was that in many instances, motivation is the best overall predictors of students' academic achievement and suggested that a decline in motivation may signify a decline in academic achievement (Gottfried, 1985).

Hence, the study seems crucial to examine the relationship between parenting styles, academic self concept, academic motivation, and academic achievement. Since the above overviews of different scholars are believed that such variables are affected students' educational successes and achievement. As far as the knowledge of scholars are concerned, there are significant researches done by different scholars about the relationship between parenting styles, self concept, academic motivation, and academic achievement.

Therefore, it is the strongest assurance of the investigation of this study and there seems no locally conducted research in the area. Thus, it is important to investigate the relationship between parenting styles, self concept, academic motivation, and academic achievement.

So, it is the firm belief of the researcher that few studies were made in foreign context, it is worth to investigate the relationship between academic self concept, academic motivation, parenting styles and academic achievement. Moreover, the researcher observed that little attention is given to the contribution of the academic self concept, academic motivation and parenting styles for academic achievement in Fasilo Secondary School. Therefore, the researcher thought that investigating the relationship between students' academic self concept, academic motivation, parenting styles and academic achievement in relation to students' gender difference is paramount important. Thus, the study attempted to answer the following basic questions:

1. Are there any significant relationship among, parenting style, academic self concept, academic motivation and students' achievement?

2. Do the parenting style, academic self concept and academic motivation have an effect on students' academic achievement?

3. Are there any significant differences between male and female students in parenting style, academic self concept, academic motivation and academic achievement?

The overall purpose of this study was to examine and to see the relationship among the parenting styles, academic self -concept, academic motivation and students' academic achievement in Fasilo secondary school. Accordingly, this study focused on the following specific objectives that indicate the direction of the research work was to find out the relationship of parenting style, academic self-concept and academic motivation with students' academic achievement, to assess the effect of parental style, academic self-concept, and academic motivation on students' academic achievement and to examine gender differences in parenting style, academic motivation, academic self concept and academic achievement. 
Asrat Dagnew

\section{MATERIALS AND METHODS}

The research design selected to fulfil this purpose was a quantitative research approach which involves correlation design. The author in this study is interested primarily to investigate the relationships between students' academic self concept, academic motivation, parenting styles and academic achievement of students at Fasilo Secondary School as well as the effect of independent variables (academic self concept, academic motivation) on students' academic achievement and lastly, to examine gender difference in parenting styles, academic motivation, academic self- concept and academic achievement.

\section{Sources of Data}

For this study, both primary and secondary sources of data were employed. The primary sources were students of Fasilo secondary school. On the other hand, the secondary source was obtained from Fasilo secondary school record office.

\section{Population, Samples and Sampling Techniques}

The target populations of this study were students who are attending their regular school in Fasilo secondary school in the academic year of 2007 E.C. In this particular study the total sample size determined is 136 students (82
Sci. Technol. Arts Res. J., July-Sep 2015, 4(3): 215-221

Male, 54 female). Then, about $14 \%$ of the total populations of the study make up a sample of the study mean and proportional allocation, i.e. each stratum (grade level) contributes to the sample number which is proportional to its size in the population.

Regarding to the sampling techniques used, the stratified random sampling technique was employed making sure that students from all grades and gender were appropriately represented.

First, the investigator formed the strata through dividing the whole target population (970 students) into some subgroup based on participant common characteristics such as grade $9^{\text {th }}$ and 10 th grade. The allocation of sample in each stratum was determined by using proportions.

Secondly, after determining the samples to be selected in each stratum, the next task was selecting gender from each grade using simple random sampling techniques (lottery) method.

Table 1 shows the population size and the number of students selected from Fasilo secondary school by considering the two grade levels.

Table 1: Sample students from the sample school

\begin{tabular}{cccccccc}
\hline \multirow{2}{*}{ No } & \multirow{2}{*}{ Grade } & \multicolumn{2}{c}{ Total number of students in the selected school } & \multicolumn{3}{c}{ A sample is taken from each school } \\
\cline { 2 - 7 } & & Male & Female & Total & Male & Female & Total \\
\hline 1 & $9^{\text {th }}$ & 295 & 205 & 500 & 41 & 29 & 70 \\
2 & $10^{\text {th }}$ & 293 & 177 & 470 & 41 & 25 & 66 \\
\hline & Total & $\mathbf{5 8 8}$ & $\mathbf{3 8 2}$ & $\mathbf{9 7 0}$ & $\mathbf{8 2}$ & $\mathbf{5 4}$ & $\mathbf{1 3 6}$ \\
\hline \multicolumn{7}{r}{}
\end{tabular}

\section{Data Gathering Instruments}

The quantitative data were collected primarily from students by employing questionnaire. Documentary analysis was also used to collect students' academic results during the first semester. Two measuring instruments were used, an adaptation of the self description questionnaire and a measure of independent variables.

Table 2: Reliability test results with Cronbach's alpha

\begin{tabular}{lccc}
\hline \multicolumn{1}{c}{ Dimensions } & Cronbanch's alpha & No of items & Remark \\
\hline Authoritative parenting style & .909 & 10 & 4 items discarded \\
Authoritarian parenting style & .772 & 10 & 2 items discarded \\
Permissive parenting style & .783 & 9 & 4 items discarded \\
Neglected parenting style & .765 & 6 & - \\
Self-concept & .823 & 20 & 4 items discarded \\
Intrinsic motivation & .885 & 12 & 3 items discarded \\
Extrinsic motivation & .810 & 12 & 2 items discarded \\
\hline \multicolumn{1}{c}{ Total } & $\mathbf{. 8 2 1}$ & $\mathbf{7 9}$ & $\mathbf{1 9}$ items discarded \\
\hline
\end{tabular}

As it is shown in table 2, 4 items from authoritative, 2 items from authoritarian, 4 items from permissive and no items from neglected parenting style, 4 items from academic self concept, 3 items from intrinsic motivation and 2 items from extrinsic motivation were discarded. In addition, restating the items to be made for the items that contained words like always, rarely, sometimes, usually since such words making confusion to the respondents during data collection were modified.

\section{Method of Data Analysis}

As far as the quantitative data are concerned, the Statistical Package for Social Sciences (SPSS) version 20 software was used for data entry and analysis. After carefully gathering the appropriate data, analysis was applied. In order to achieve the objective of the study, mean, standard deviations, Pearson product moment correlation, multiple regression and two samples t-test analysis were applied.

Therefore, to understand whether there is a significant relationship between parent styles, academic selfconcept, academic motivation and a student academic achievement, Pearson product moment correlation was employed. 


\section{Asrat Dagnew}

To determine the mean score difference between male and female students on parenting styles, academic selfconcept, academic motivation and academic achievement dimensions two samples independent t-test was employed.

To see the influence of independent variables (academic self-concept, parenting styles and academic motivation) on the dependent variable (academic achievement), multiple regressions were employed.
Sci. Technol. Arts Res. J., July-Sep 2015, 4(3): 215-221

\section{RESULTS}

Inter - correlation among Predictor Variables and Academic Achievement

The mean, standard deviation and inter-correlation among the authoritative, authoritarian permissive and neglected parenting styles, academic self -concept, academic motivation and students' academic achievement were shown in table 3.

Table 3: The Mean, Std. Deviation and interrelationship among predictor variables and academic achievement

\begin{tabular}{|c|c|c|c|c|c|c|c|c|c|c|}
\hline Variables & Mean & Std. Deviation & 1 & 2 & 3 & 4 & 5 & 6 & 7 & 8 \\
\hline Authoritative 1 & 42.02 & 7.361 & 1 & & & & & & & \\
\hline Authoritarian 2 & 38.58 & 6.728 & $0.280^{* *}$ & 1 & & & & & & \\
\hline Permissive 3 & 27.20 & 5.980 & $-0.198^{*}$ & 0.113 & 1 & & & & & \\
\hline Neglected 4 & 16.44 & 5.526 & $-0.509^{* *}$ & -0.074 & $0.569^{* *}$ & 1 & & & & \\
\hline Self-concept 5 & 75.35 & 9.025 & 0.105 & 0.141 & 0.115 & -0.098 & 1 & & & \\
\hline Intrinsic_mot 6 & 49.45 & 6.986 & $0.248^{* *}$ & $0.241^{* *}$ & -0.021 & -0.109 & $0.634^{* *}$ & 1 & & \\
\hline Extrinsic_mot 7 & 46.71 & 7.635 & $0.231^{* *}$ & $0.256^{* *}$ & 0.037 & -0.017 & $0.292^{* *}$ & $0.447^{* *}$ & 1 & \\
\hline Achievement 8 & 62.39 & 10.715 & $0.327^{* \star}$ & $-0.225^{*}$ & $-0.366^{* *}$ & 0.045 & $0.209^{*}$ & $0.248^{* *}$ & $0.222^{*}$ & 1 \\
\hline
\end{tabular}

${ }^{* *}$. Correlation is significant at the 0.01 level (2-tailed) and *. Correlation is significant at the 0.05 level (2-tailed)

Pearson Coefficient of Correlation is the most commonly used measure of finding correlations between two or more variables. A correlation exists between two variables when one of them is related to the other in some way. Correlation focuses primarily of association, while regression is designed to help make predictions. Consequently, the correlation does not attempt to establish any cause and effect.

As it is shown in table 3, Analysis shows that the correlation between predictor variables and academic achievement verified that academic achievement correlated positively and significantly with authoritative $(r=0.327, p<0.01)$, self-concept $(r=0.209, p<0.05)$ intrinsic motivation $(r=0.248 p<0.01)$ and extrinsic motivation $(r=0.222 p<0.05)$. This could be interpreted that authoritative parenting style, self -concept, intrinsic motivation and extrinsic motivation might increase if they scored higher on students' academic achievement.

Academic achievement Correlated negatively and significantly with authoritarian $(r=-0.225, p<0.05)$ and permission $(r=-0.366, p<0.01)$. The values of ' $r$ ' for of this style are at a low level. And However the correlation between academic achievement and neglected parenting style is correlated positively, but not statistically significant $(r=0.045, p>0.05)$. This means that, there is an existed relationship between academic achievement and neglected parenting style, but the relationship is not significant.

The correlation between predictor variables indicated that extrinsic motivation correlated positively and significantly with authoritative $(r=0.231, p<0.01)$, authoritarian $(\mathrm{r}=0.256, \quad p<0.01)$, self-concept $(\mathrm{r}=0.292$, $p<0.01$ ) and intrinsic motivation ( $r 0=0.447, p<0.01$ ), it is not significantly positively correlated with permissive ( $r=$ $0.037, p>0.05$ ). Extrinsic motivation Correlated negatively and not significantly with neglected parenting style ( $r=-$ $0.017, p>0.05)$

Intrinsic motivation correlated positively and significantly with authoritative $(r=0.248, \quad p<0.01)$, authoritarian $(r=0.241, p<0.01)$ and self-concept $(r=0.634$, $p<0.01)$. Intrinsic motivation correlated negatively and not significantly with permissive $(r=-0.021, p>0.05)$ and neglected $(r=-0.109, p>0.05)$.

The correlation between predictor variables indicated that self-concept correlated positively and not significant with authoritative $(r=0.105, p>0.05)$, authoritarian $(r=0.141, p>0.05)$, permissive parenting style $(r=0.115$, $p>0.05)$ and correlate negatively and not significant with neglected $(r=-0.098, p>0.05)$

Similarly, there was a statistically significant and positive relationship between authoritative and authoritarian $(r=0.280, p<0.05)$. There were statistically significant positive relationship between permissive and neglected $(r=0.569, p<0.05)$.

Permissive parenting styling correlated positively with authoritarian ( $r=0.113, p>0.05)$ and were not significant and negative relationship and significant with authoritative $(r=-0.198, p<0.05)$. However, the neglected parenting styling correlated negatively and significantly with authoritative $(r=-0.509, \quad p<0.05)$ and authoritarian parenting styling $(r=-0.074, p>0.05)$ and were not significant.

\footnotetext{
Multiple Regression of Predictor Variables on Students' Academic Achievement

The effect of authoritative, authoritarian permissive and neglected parenting styles, academic self concept, and academic motivation on students' academic achievement was examined using multiple Regressions, as shown in table 4 .

The result on the above table shows, Authoritative have a positive and significant effect on students academic achievement $(\beta=0.331, p<0.05)$. In addition, although the effect is very weak, authoritarian and Permissive parenting styles had a significant and negative effect on the academic achievement $(\beta=-0.394, p<.05)$ and $(\beta=-0.242, p<0.05)$ respectively.
} 
Table 4: Multiple Regression of predictor variables on students' academic achievement

\begin{tabular}{|c|c|c|c|c|c|c|c|c|c|c|}
\hline \multirow[t]{2}{*}{ Variables } & \multirow[t]{2}{*}{$\mathbf{R}$} & \multirow{2}{*}{$\begin{array}{c}\mathbf{R} \\
\text { Square }\end{array}$} & \multicolumn{2}{|c|}{$\begin{array}{l}\text { Unstandardized } \\
\text { Coefficients }\end{array}$} & \multirow{2}{*}{$\begin{array}{c}\begin{array}{c}\text { Standardized } \\
\text { Coefficients }\end{array} \\
\text { Beta } \\
\end{array}$} & \multirow[t]{2}{*}{ t-test } & \multirow{2}{*}{ DF } & \multirow[t]{2}{*}{ Sig. } & \multirow[t]{2}{*}{ f-test } & \multirow[t]{2}{*}{ Sig. } \\
\hline & & & B & Std. Error & & & & & & \\
\hline Authoritative & & & 0.484 & 0.108 & 0.331 & 4.486 & 128 & 0.000 & & \\
\hline Authoritarian & & & -0.631 & 0.116 & -0.394 & -5.433 & 128 & 0.000 & & \\
\hline Permissive & & & -0.435 & 0.127 & -0.242 & -3.439 & 128 & 0.001 & & \\
\hline Neglectful & 0.690 & 0.476 & 0.359 & 0.084 & 0.022 & 1.327 & 128 & 0.187 & 15.811 & 0.000 \\
\hline Self-concept & & & 0.393 & 0.087 & 0.329 & 4.522 & 128 & 0.000 & & \\
\hline Intrinsic-Mot & & & 0.397 & 0.106 & 0.282 & 3.749 & 128 & 0.000 & & \\
\hline Extrinsic-Mot & & & 0.368 & 0.121 & 0.238 & 3.043 & 128 & 0.003 & & \\
\hline
\end{tabular}

On the other hand Neglectful did not have a significant direct effect on the academic achievement of students ( $\beta$ $=.022, p>0.05$ ). More specifically, students who perceived their parents as authoritative were found to have significantly higher academic achievement when compared to their counterparts who described their parents as non-authoritative (i.e., authoritarian, indulgent, or neglectful).

Although the result revealed Academic self-concept had a significant and positive direct effect on the academic achievement $(\beta=0.329, p<0.05)$. These indicate that academically higher self- concept, students had higher academic achievement compared to their counterpart students who had lower academic selfconcept. Similarly, intrinsic motivation had a significant and positive direct effect $(\beta=0.282, p<0.05)$ on academic achievement, suggesting that students with higher achievement (academic) intrinsic motivation had higher academic achievement. Extrinsic motivation had a significant positive direct effect on the academic achievement $(\beta=0.329, p<.05)$.

The variables (Authoritative parenting style, Academic self-concept, intrinsic motivation and extrinsic motivation) are treated in this study were positively and significantly related to each other. In other word, the variables show a change in one variable may contribute to a change in another variable in the same direction. Evidence suggests that when two variables or sets of data fluctuate in the same direction, i.e. as one increases, so does the other, or as one decreases, so does the other, a positive relationship is said to exist. For example, as table 4 above states a change in authoritative parenting style, selfconcept, intrinsic motivation and extrinsic motivation may bring change in students' academic achievement. Therefore, the variables have a positive effect and significant with academic achievement.

Analysis on table 4, indicated that all composite variables, authoritative, authoritarian, permissive parenting styles, academic self concept, academic motivation were positive and negative with students' academic achievement significantly $(\mathrm{f}=15.811, p<0.05)$. This means authoritative parenting style, self -concept, intrinsic motivation and extrinsic motivation are positive and significant influence students' academic achievement ( $\mathrm{T}=4.486, \quad p<0.05, \mathrm{~T}=4.522, \quad p<0.05, \mathrm{~T}=-3.749, \quad p<0.05$, and $\mathrm{T}=3.043, P<0.05$ respectively). On the other hand authoritarian parenting style and permissive parenting style are negatively and significantly with students' academic achievement $(\mathrm{T}=-5.433, p<0.05$ and $\mathrm{T}=-3.439$, $p<0.05$ respectively). However the Neglectful parenting style has not significant with students' academic achievement ( $T=1.327, p>0.05)$.

This also strengthen by composite regression analysis , authoritative, authoritarian permissive and neglected parenting styles, academic self -concept and academic motivation as predictor of students' academic achievement in R- square of .476, which implies that all of the predictor variables accounted for $47.6 \%$ of the variation in academic achievement. So that great attention is giving for the contribution of parenting styles, academic self-concept and academic motivation for academic achievement.

If so in order to the degree of each predictor variables that making variance in the criterion variable, to the single -variant regression was applied and the detailed results were presented as follow.

Table 5: Leaner Regression statistics of predictor variables on students' academic achievement

\begin{tabular}{lccccc}
\hline \multicolumn{1}{c}{ Variables } & $\mathbf{R}$ & $\begin{array}{c}\mathbf{R} \\
\text { Square }\end{array}$ & f-test & t-test & Sig. \\
\hline Authoritative & 0.327 & 0.107 & 15.294 & 3.911 & 0.000 \\
Authoritarian & 0.209 & 0.044 & 6.921 & -2.611 & 0.010 \\
Permissive & 0.366 & 0.134 & 19.757 & -4.45 & 0.000 \\
Neglected & 0.045 & 0.002 & 0.259 & 0.509 & 0.132 \\
self-concept & 0.225 & 0.050 & 6.802 & 2.608 & 0.010 \\
Intrinsic motivation & 0.246 & 0.051 & 6.905 & 2.628 & 0.001 \\
Extrinsic motivation & 0.208 & 0.040 & 5.265 & 2.295 & 0.004 \\
\hline \multicolumn{5}{c}{$p^{*}<0.05$}
\end{tabular}

As can be seen from table 5 , the achieved result through single - variant regression test indicated that the independent variable permissive parenting style, authoritative parenting style, intrinsic motivation Authoritarian parenting style, self-concept and ,extrinsic motivation were effect academic achievement significantly resulted in $\mathrm{R}$ square $(0.134,0.107,0.051$, $0.050,0.44$ and 0.040 ) respectively. This implies that variable permissive parenting style, authoritative parenting style, intrinsic motivation, Authoritarian parenting style, self-concept and extrinsic motivation accounted for $(13.4,10.7,5.1,5.0,4.4$, and $4.0 \%)$ respectively. However, the independent variable neglected parenting style accounted $(0.2 \%)$ did not affect and predict academic achievement relatively not statistical significant with neglectful parenting style.

On the other hand, the result of f-test and t-test value showed that there was positively and negative significant 


\section{Asrat Dagnew}

difference between independent variables (authoritative parenting style, Authoritarian parenting style, permissive parenting style, academic self-concept intrinsic motivation and extrinsic motivation) and academic achievement. However neglectful parenting style was not significant difference with academic achievement.

Gender Difference in Predictor Variables and Academic Achievement

As indicated in table 6, the results of two sample t-test show that, there is a significance difference between female and male students in Authoritative $(\mathrm{t}=4.205, p$ $<0.05)$, Authoritarian $(\mathrm{t}=3.041, \quad p<0.05), \quad$ Permissive $(\mathrm{t}=4.274, p<0.05)$, Self-concept $(\mathrm{t}=3.034, p<0.05)$, Intrinsic motivation $(\mathrm{t}=2.744, p<0.05)$ and Extrinsic motivation
Sci. Technol. Arts Res. J., July-Sep 2015, 4(3): 215-221

$(t=3.311, p<0.05)$. Which means Female students scored high mean score than male counterparts in Authoritative, Authoritarian, Permissive, Self-concept, Intrinsic motivation and extrinsic motivation. These results shows that female have high authoritative parenting styles, Authoritarian parenting styles, Permissive parenting styles, Self-concept, Intrinsic motivation and extrinsic motivation. However, there was no difference mean between males and females with respect to neglectful parenting style and academic achievement was found to be statistically not significant $(t=-3.840, p>0.05)$. On the other hand, male students scored highly mean than their females counterpart in academic achievement.

Table 6: Gender Difference in Predictor Variables and Academic Achievement

\begin{tabular}{|c|c|c|c|c|c|c|c|}
\hline & Sex & $\mathbf{N}$ & Mean & Std. Deviation & t-test & Df & Sig.(2-tailed) \\
\hline \multirow{2}{*}{ Authoritative } & Female & 52 & 41.25 & 5.527 & \multirow{2}{*}{4.205} & \multirow{2}{*}{128} & \multirow{2}{*}{0.000} \\
\hline & Male & 78 & 36.50 & 6.778 & & & \\
\hline \multirow{2}{*}{ Authoritarian } & Female & 52 & 40.69 & 5.540 & \multirow{2}{*}{3.041} & \multirow{2}{*}{128} & \multirow{2}{*}{0.010} \\
\hline & Male & 78 & 37.22 & 6.882 & & & \\
\hline \multirow{2}{*}{ Permissive } & Female & 52 & 30.44 & 5.070 & \multirow{2}{*}{4.274} & \multirow{2}{*}{128} & \multirow{2}{*}{0.000} \\
\hline & Male & 78 & 25.81 & 6.629 & & & \\
\hline \multirow{2}{*}{ Neglectful } & Female & 52 & 16.44 & 4.869 & \multirow{2}{*}{-3.840} & \multirow{2}{*}{128} & \multirow{2}{*}{0.132} \\
\hline & Male & 78 & 16.44 & 5.561 & & & \\
\hline \multirow{2}{*}{ Self-concept } & Female & 52 & 78.6923 & 6.047 & \multirow{2}{*}{3.034} & \multirow{2}{*}{128} & \multirow{2}{*}{0.010} \\
\hline & Male & 78 & 74.279 & 9.4108 & & & \\
\hline \multirow{2}{*}{ Intrinsic motivation } & Female & 52 & 51.90 & 5.613 & \multirow{2}{*}{2.744} & \multirow{2}{*}{128} & \multirow{2}{*}{0.001} \\
\hline & Male & 78 & 48.68 & 7.125 & & & \\
\hline \multirow{2}{*}{ Extrinsic motivation } & Female & 52 & 50.90 & 5.699 & \multirow{2}{*}{3.311} & \multirow{2}{*}{128} & \multirow{2}{*}{0.004} \\
\hline & Male & 78 & 47.03 & 7.047 & & & \\
\hline \multirow{2}{*}{ Academic Achievement } & Female & 52 & 58.02 & 9.456 & \multirow{2}{*}{-3.850} & \multirow{2}{*}{128} & \multirow{2}{*}{0.000} \\
\hline & Male & 78 & 65.12 & 10.830 & & & \\
\hline
\end{tabular}

\section{DISCUSSION}

Inter-Correlations between Predictor Variables and Academic Achievement

Result of the correlation analysis clearly showed that there are a positive and negatively significant relationship between parenting styles (authoritative, authoritarian or permissive) and academic achievement. This means that students whose parenting styles (authoritative, authoritarian or permissive) were scored significantly higher academic achievement. But neglectful parenting style was not significantly related with academic achievement. In details, Pearson correlation analysis showed that authoritative style had a positive and significant influence on academic achievement among students. Students who had parent with authoritative style were more successful in school. The results are consistent with Park and Bauer (2002), Attaway and Bry (2004), which found that authoritative parenting style promote school achievement.

\section{Correlation between Predictor Variables}

As shown in table 3 , on the positive and significantly related of authoritative parenting style with intrinsic and extrinsic academic motivation, but was not significant relation with self concept. In line with the results, pervious findings as Leung and Kwan (1998) examined motivational orientation as a mediator between parenting style and self-perceived academic competence in a study of adolescents using measures constructed for the purposes of their study. Ginsberg and Bronstein, (1993) as cited in Fox and Zimmerman, (2008) discovered that (authoritative) families were positively associated with both intrinsic motivation and academic performance.

Parenting Styles, Academic Self-concept \& Academic Motivation as Predictors of Academic Achievement

The regression analysis indicated that there was a significant contribution of parenting styles (authoritative, authoritarian permissive); self-concept and academic motivation were affected academic achievement. The finding of this research shown that parenting styles (authoritative, authoritarian, and permissive), academic self concept and academic motivation (intrinsic and extrinsic motivation) are positively and negatively affected on academic achievement. This means authoritative parenting style, self -concept, intrinsic motivation and extrinsic motivation had a positive and significant influence on academic achievement. On the other hand, authoritarian parenting style and permissive parenting style had a negative and significant influence on academic achievement.

Gender Difference between Predictor Variables and Academic Achievement

As the results of the two samples t-test revealed, there is a significant sex difference in authoritative, 


\section{Asrat Dagnew}

authoritarian, permissive, neglected, self-concept, academic intrinsic motivation, extrinsic motivation and academic achievement. From this, the two sample t-test indicated that, female students scored higher mean score than male counterparts in authoritative, authoritarian, permissive, self-concept, academic intrinsic motivation and extrinsic motivation. On the other hand, these study shows, male students scored higher mean score than female counterparts in academic achievement. However, there was no difference mean between males and females with respect to neglectful parenting style and was found not to be statistically significant.

\section{CONCLUSION}

Consistent with the findings of the study, the following conclusions could be drawn from the result, there was statistically significant positive and negative correlation between academic achievement and the predictor variables except neglectful parenting style i.e., they contributed positively to students' academic success and achievement. This implied that parents' attitude and style have a significant influence on the school achievement of their children, especially when they are involved in their childrens' education and monitor their children's after school works. The findings of the present study implied that parents play a significant role in determining the level of academic achievement among students. Thus, it is essential that parents are equipped with appropriate knowledge and skills so that they can provide better guidance for their students' positive development, especially in academic achievement.

As shown in the results of this study, the authoritative parenting style, students' academic self-concept, academic intrinsic motivation and extrinsic motivation have a positive effect on academic achievement. Therefore, students having high authoritative parenting style, self-concept, academic intrinsic motivation and extrinsic motivation in turn will have high academic achievement. On other hand, authoritarian and permissive parenting styles are negative effect on students' academic achievement. From the findings, one can conclude that authoritative parenting style, self-concept, intrinsic motivation and extrinsic motivation have strong effort on students' academic achievement. The study also reported that there was a significant means score difference in parenting styles (authoritative, authoritarian, and permissive), self-concept, intrinsic academic motivation, extrinsic academic motivation and academic achievement between male and female. In relation to this, female students have relatively higher levels of authoritative, authoritarian, permissive, self-concept, intrinsic academic motivation and academic extrinsic. On the other hand, male students have relatively higher levels of academic achievement and not significant difference between male and female of neglectful parenting style. From this, we can admit that male students have higher academic performance than female students in the school.

Finally, the findings of the present study implied that parents play a significant role in determining the level of academic achievement among students. Thus, it is essential that parents are equipped with appropriate knowledge and skills so that they can provide better guidance for their students' positive development, especially in academic achievement.
Sci. Technol. Arts Res. J., July-Sep 2015, 4(3): 215-221

\section{Conflict of Interest}

Author declared no conflict of interest.

\section{REFERENCES}

Amare Sahile. (2001). Effects of Students' Academic Competence, Self-Determination and Motivation School Performance in Tana Haiq Secondary School. The Ethiopian Journal of Education XXI.

Attaway, M.N. and Bry, F.B. (2004). Parenting Style and Black Adolescents' Academic Achievement. Journal of Black Psychology 30(2): 229-249.

Bandura, A. (1997). Self-efficacy and academic achievement. Harvard Mental Health Letter 13(9): 4-7.

Broussard, S.C. (2002). The Relationship Between Classroom motivation and academic achievement in first and third grades. Unpublished Thesis, the School of Human Ecology. Louisiana State University, 1989. Available from: http://edu/docs/available.etd-1107102185505/unrestricted/Broussard thesis.pdf

Fox, K.M. and Zimmerman, L. (2008). The Relationships between Socioeconomic Status, Parenting Styles, and Motivation Orientation. Retrieved from http://www.graduateschool.owm.edu/formsanddownloads/ researchers/mcnair/2002/ fox.pdf

Gottfried, A.E. (1985). Academic Intrinsic motivation in Elementary and Junior High School Students. Journal of Education psychology 77(6): 631-645.

Kambel, S .(2009). Influence of Parental Relationship and self-Concept on Academic Achievement of PUC Students. M.Sc. (Degree) Thesis. University of Agricultural Sciences, Dharwad. Department of Human Development. Retrieved from http://etd. uasd.edu/abst/ th9874.pdf

Leung, P.W. and Kwan, K.S. (1998). Parenting styles, motivation orientations, and self-perceived competence: $A$ mediational model. Merrill-Palmer Quarterly 44(1): 1-19.

Park, H.S. and Bauer, S. (2002). Parenting practices, ethnicity, socioeconomic status and academic achievement in adolescents. School Psychology International 23(4): 386-396.

Tella. A. (2007). The Impact of Motivation on Students' Academic Achievement and Learning Outcomes in Mathematics among secondary school students in Nigeria. Eurasia Journal of Mathematics, science and Technology Education 3(2):149-156.

Watabe, K. (2011). The influence of parenting on children's academic achievement: comparison between the United States and Japan. A Thesis Presented to the Faculty of California State University, Chico. Retrieved from htt://www.csuchicospace.calstat.edu/handle 110211.4/347.watabe.pdf.

Wool folk A. (1995). Educational Psychology, $6^{\text {th }}$ edition. USA: Allyn and Bacon.

Zimmerman, B.J. (2002). Becoming a self-regulated learner and practice. Theory into Practice 41(2): 64-70. 